\title{
Single or Multiple Familial Cognitive risk Factors in Schizophrenia?
}

Citation for published version (APA):

Krabbendam, A. C., Marcelis, M., Delespaul, P. A. E. G., Jolles, J., \& van Os, J. J. (2001). Single or Multiple Familial Cognitive risk Factors in Schizophrenia? American Journal of Medical Genetics, 105, 183-188. https://doi.org/10.1002/ajmg.1197

Document status and date:

Published: 01/01/2001

DOI:

10.1002/ajmg.1197

Document Version:

Publisher's PDF, also known as Version of record

\section{Please check the document version of this publication:}

- A submitted manuscript is the version of the article upon submission and before peer-review. There can be important differences between the submitted version and the official published version of record.

People interested in the research are advised to contact the author for the final version of the publication, or visit the DOI to the publisher's website.

- The final author version and the galley proof are versions of the publication after peer review.

- The final published version features the final layout of the paper including the volume, issue and page numbers.

Link to publication

\footnotetext{
General rights rights.

- You may freely distribute the URL identifying the publication in the public portal. please follow below link for the End User Agreement:

www.umlib.nl/taverne-license

Take down policy

If you believe that this document breaches copyright please contact us at:

repository@maastrichtuniversity.nl

providing details and we will investigate your claim.
}

Copyright and moral rights for the publications made accessible in the public portal are retained by the authors and/or other copyright owners and it is a condition of accessing publications that users recognise and abide by the legal requirements associated with these

- Users may download and print one copy of any publication from the public portal for the purpose of private study or research.

- You may not further distribute the material or use it for any profit-making activity or commercial gain

If the publication is distributed under the terms of Article $25 \mathrm{fa}$ of the Dutch Copyright Act, indicated by the "Taverne" license above, 


\title{
Single or Multiple Familial Cognitive Risk Factors in Schizophrenia?
}

\author{
Lydia Krabbendam, ${ }^{1}$ Machteld Marcelis, ${ }^{1}$ Philippe Delespaul, ${ }^{1}$ Jelle Jolles, ${ }^{1}$ and Jim van Os ${ }^{1,2 *}$ \\ ${ }^{1}$ Department of Psychiatry and Neuropsychology, Maastricht University, European Graduate School of Neuroscience, \\ Maastricht, The Netherlands \\ ${ }^{2}$ Institute of Psychiatry, London, UK
}

\begin{abstract}
The fact that relatives of patients with schizophrenia display subtle cognitive abnormalities suggests genetic transmission of an underlying cognitive endophenotype. It was examined to what extent the cognitive abnormalities that discriminate patients and relatives from controls do so independently of each other, and independent of IQ. Neuropsychological measures were assessed in 50 patients with schizophrenia, 50 first-degree relatives of patients with schizophrenia, and 50 healthy controls. The assessment focused on episodic memory, attentional span, simple and complex speed of information, and semantic memory. Factor analysis of the cognitive test results yielded four factors reflecting speed, episodic memory, working memory, and semantic fluency. Performance of the relatives was intermediate to that of the patients and the controls after adjustment for age, sex, educational level, and IQ. For both patients and relatives, speed of information processing, working memory, and episodic memory independently discriminated from control performance, with a similar pattern in the order of the size of the effects. The results suggest the existence of more than one familial cognitive risk factor for schizophrenia. Independent familial cognitive risk factors may represent separate causal influences or separate indicators of risk related to the same genetic mechanism.

(c) 2001 Wiley-Liss, Inc.
\end{abstract}

Grant sponsor: Dutch Brain Society; Grant sponsor: Dutch Prevention Fund.

*Correspondence to: Jim van Os, Department of Psychiatry and Neuropsychology, Maastricht University, European Graduate School of Neuroscience, PO Box 616, 6200 MD Maastricht, The Netherlands. E-mail: j.vanos@sp.unimaas.nl

Received 18 August 2000; Accepted 8 January 2001

Published online 23 February 2001

$\begin{array}{ll}\text { KEY WORDS: } & \begin{array}{l}\text { schizophrenia; genetics; } \\ \text { neuropsychology; endo- } \\ \text { phenotypes; relatives }\end{array}\end{array}$

\section{INTRODUCTION}

First-degree biological relatives of patients with schizophrenia have an approximately 10 -fold risk of developing schizophrenia [Kendler and Diehl, 1993]. Cognitive vulnerability indicators that are heritable should also be present in relatives, at least in those who carry the risk for schizophrenia.

There is evidence that relatives of patients with schizophrenia exhibit subtle cognitive deficits [Kremen et al., 1994], including impairments of attention [Harris et al., 1996; Chen and Faraone, 2000], executive functioning [Faraone et al., 1999], spatial working memory [Park et al., 1995], and verbal memory [Goldberg et al., 1995]. It is not known, however, whether such findings in the various domains of cognitive functioning reflect the presence of one underlying global cognitive deficit, or whether they each independently represent a discrete cognitive risk factor that is transmitted in the families of patients with schizophrenia. It has been suggested that there may be at least three domains of neuropsychological deficit in the non-psychotic relatives of patients that are stable over time: auditory attention, verbal memory, and executive functioning [Faraone et al., 1995b; Faraone et al., 1999]. If there were discrete cognitive risk factors, one would expect that the various cognitive deficits in the relatives of patients occur both independent of each other and independent of IQ. The present study investigated these issues in patients with schizophrenia and their biological relatives. To this end, we used a comprehensive battery, guided by previous literature [Gold and Weinberger, 1995; Schatz, 1998; Faraone et al., 1999; Mohamed et al., 1999; Chen and Faraone, 2000] on the domains most frequently observed to be compromised in schizophrenia patients and their relatives. 


\section{MATERIALS AND METHODS}

\section{Subjects}

The individuals assessed in this study were participants in a larger study, the Maastricht Psychosis Study. Initial selection criteria for all subjects were the lifetime prevalence of a period of psychosis (at least two weeks) in clear consciousness, according to the Research Diagnosis Criteria (RDC) [Spitzer et al., 1978], or being a first-degree relative of a patient. Inclusion criteria for all subjects were to be between the ages of 18 to 55 years; to have sufficient enough command of the Dutch language to understand instructions and informed consent; and to receive normal results for physical examination, ECG, and laboratory tests. Exclusion criteria were endocrine, cardiovascular, or brain disease; use of alcohol in excess of five standard units per day; weekly use of illicit drugs; and history of head injury with loss of consciousness. Written informed consent, conforming to the local ethics committee guidelines, was obtained from all subjects.

The total sample included 50 patients with psychosis, 50 non-psychotic first-degree relatives, and 50 healthy controls. Patients, relatives, and controls were interviewed with the Brief Psychiatric Rating Scale (BPRS) [Overall and Gorham, 1962; Lukoff et al., 1986] and the Positive and Negative Syndrome Scale (PANSS) [Kay et al., 1992], and additionally screened for symptoms listed in the Operational Criteria Checklist for Psychotic Disorder (OCCPI) [McGuffin et al., 1991]. Where necessary, additional information was derived from case notes and interviews with the responsible medical officer. Using the combined information, the computerized program OPCRIT [McGuffin et al., 1991] was used to yield RDC diagnoses. There were 40 cases of schizophrenia and 10 cases of schizo-affective disorder among the patients with psychosis. Six first-degree relatives were diagnosed as having major depression. Two of the six relatives with major depression were from the families of schizo-affective patients. Of the 50 non-psychotic relatives, there were six mothers, six fathers, 20 sisters, 17 brothers, and one son. The study population originated from 66 families with at least one patient with psychosis. Of the 66 families, 40 families contributed one case or one relative, one family contributed two relatives, one family contributed three relatives, and 24 contributed at least one case and one relative.

Patients were recruited from the catchment area Community Mental Health Center and the out-patient clinic of the catchment area psychiatric hospital. Relatives were sampled through participating patients or through associations for relatives of patients with psychotic illness. Relatives had to be free from a lifetime history of psychosis. Control subjects were recruited from the general population through random mailings in the local area from a listing of all eligible individuals in the general population. None of the controls had a history of psychosis or a history of psychosis in a first-degree relative, and none of them used psychotropic medication.
The patients were frequency-matched with the control subjects on age, but as a group they were somewhat younger than the relatives (Table I). The three groups were frequency-matched for sex and educational level, which was measured on an 8-point scale, ranging from primary school to university degree [De Bie, 1987]. IQ score was significantly lower in the patient group compared to both the relatives and the control group. All patients were in remission or in partial remission, defined as not in need of hospital admission. The mean total score of the patient group on the BPRS [Overall and Gorham, 1962; Lukoff et al., 1986 ] was $39.1(\mathrm{SD}=10.4)$. Fourty-eight patients were using antipsychotic medication, 17 were using benzodiazepines, nine were using antidepressants, and three were using lithium. Two patients did not use any psychoactive medication. Two of the relatives were using antidepressants and three were using benzodiazepines.

\section{Neuropsychological Assessment}

The neuropsychological assessment was directed at the following cognitive domains: episodic memory, semantic memory, attentional span, and simple and complex information processing. The tests were administered to all subjects.

The Auditory Verbal Learning Task (AVLT) [Brand and Jolles, 1985; Lezak, 1995] was used to evaluate memory storage and retrieval of information in episodic memory. The forward and backward Digit Spans from the Wechsler Adult Intelligence Scale-Revised [Wechsler, 1981] were used as measures of attentional span [Lezak, 1995]. Tests to measure the speed of information processing were the Stroop Color-Word Test (SCWT) [Stroop, 1935], the Concept Shifting Test (CST) [Houx et al., 1991], which is a modified version of the Trailmaking Test [Reitan, 1958], and the Letter Digit Substitution Test (LDST), which is a modified version of the Symbol Digit Modalities Test [Smith, 1968]. Speed of complex information processing was assessed using the interference task of the SCWT and the number/letter shifting task of the CST. Word Fluency was used to evaluate strategy-driven retrieval from semantic memory. For example, subjects had to generate as many animal names as possible in one minute [Lezak, 1995].

In order to obtain a measure of general intelligence, we used the shortened form of a widely used Dutch intelligence test, the Groningen Intelligence Test (GIT) [Luteijn and van der Ploeg, 1983]. This test yields results that are comparable to those of the Wechsler Adult Intelligence Scale-Revised [Wechsler, 1981]. Three subtests have proven to yield a good approximation of full-scale IQ [Luteijn and van der Ploeg, 1983].

\section{Statistical Analysis}

Statistical analyses were performed using STATA, version 6 [STATA, 1999]. Initial pairwise group comparisons were performed using one-way analysis of variance with the Tukey multiple comparison procedure. Skewed dependent variables were subjected 
TABLE I. Means (Standard Deviations) and Summary Statistics of Participant Characteristics

\begin{tabular}{|c|c|c|c|c|c|c|c|c|c|}
\hline & \multicolumn{2}{|c|}{$\begin{array}{l}\text { Patient } \\
(\mathrm{n}=50)\end{array}$} & \multicolumn{2}{|c|}{$\begin{array}{c}\text { Relative } \\
(\mathrm{n}=50)\end{array}$} & \multicolumn{2}{|c|}{$\begin{array}{c}\text { Control } \\
(\mathrm{n}=50)\end{array}$} & \multirow{2}{*}{$\begin{array}{c}F \\
\mathrm{df}=2,146\end{array}$} & \multirow[b]{2}{*}{$\mathrm{p}$} & \multirow{2}{*}{$\begin{array}{l}\text { Tukey- } \\
\text { HSD test }\end{array}$} \\
\hline & Mean & (SD) & Mean & (SD) & Mean & (SD) & & & \\
\hline Age & 31.2 & $(7.5)$ & 36.9 & (11.2) & 35.0 & $(8.9)$ & 5.3 & 0.01 & $1<2$ \\
\hline Age range & $20-48$ & & $19-55$ & & $21-50$ & & & & \\
\hline $\operatorname{Sex}(M / F)$ & $26 / 24$ & & $25 / 25$ & & $25 / 25$ & & & & \\
\hline Level of education & 3.7 & (1.4) & 4.5 & (1.8) & 4.4 & (1.7) & 3.12 & 0.05 & \\
\hline IQ score & 103.8 & (12.7) & 115.0 & (12.5) & 113.4 & (11.5) & 12.30 & 0.00 & $1<2,3$ \\
\hline BPRS & 39.1 & (10.3) & 28.4 & $(5.2)$ & 25.6 & (2.3) & 52.3 & 0.00 & $1<2,3$ \\
\hline \multicolumn{10}{|l|}{ Age at first } \\
\hline Psychotic symptoms & 22.0 & $(5.7)$ & & - & & & - & & \\
\hline
\end{tabular}

to log transformations to achieve normality (SCWT and CST). To reduce the number of dependent test variables, a principal component factor analysis followed by varimax rotation was performed on the data of the total study sample. Factors with an eigenvalue greater than unity were retained, and regression factor scores with mean zero and unity standard deviation were produced for each subject for each cognitive factor.

Regression models of neuropsychological dependent variables were examined to assess the effect of group $(0=$ controls, $1=$ relatives, and $2=$ patients $)$ on cognitive performance. In these analyses, the group variable was used as a continuous indicator of increase in schizophrenia risk. Data that are grouped according to family are, in statistical terms, part of a multilevel structure, with level-one units (individuals) being clustered into level-two units (families). Since individuals from the same family are more similar to each other than individuals from different families, the variation of cognitive functioning is smaller than if it were completely random. Conventional regression technique cannot take into account the variance components at two different levels. Therefore, a multilevel random regression model was used with a twolevel hierarchical structure. All analyses were adjusted for age, sex, and level of education. Effect sizes were expressed as the regression coefficient (B).

To investigate which cognitive factor was the strongest, independent predictor of group membership, logistic regression analyses yielding odds ratios (OR) were performed, comparing patients versus controls, and relatives versus controls, and entering all neuropsychological variables together in the equation so that the effect of each was adjusted for the three others. To control for the influence of generalized decline, these analyses were additionally corrected for IQ-score. Because major depression can be associated with cognitive deficits, we also performed the analysis with these subjects excluded.

\section{RESULTS}

Before analysis, the cognitive variables were examined for fit between their distributions and the assumptions of multivariate analysis. In five subjects (four from the patient group, one from the control group), one or two univariate outliers were found (indicated by z-scores larger than 3.29). These values were replaced by the highest group value next to the outlier. No multivariate outliers could be identified according to the criterion of Mahalanobis distance.

The PCA suggested a robust four-factor solution, which accounted for $74 \%$ of the variance. All variables of the SCWT and the LDST loaded strongly on the first factor (factor loadings from 0.59 to 0.88 ), which we termed speed. All variables of the AVLT loaded strongly on the second factor (factor loadings from 0.89 to 0.93 ), which we termed episodic memory. Both fluency tasks (animals and professions) loaded on the third factor (factor loadings from 0.83 to 0.87 ), which we termed semantic fluency. All variables of the CST and both Digit Span tasks loaded strongly on the fourth factor (factor loadings from 0.69 to 0.73 ), which can thus be construed as that area of focused information processing that is used under conditions of time constraint. We interpreted this factor as the working memory component common to the CST and Digit Span tasks (hereafter referred to as working memory component). These four factors were used in the analyses, with higher scores indicating poorer performance. One-way analysis of variance indicated significant differences between the groups on speed $(\mathrm{F}=13.61, \mathrm{df}=2,147$, $P=0.00)$, episodic memory $(\mathrm{F}=3.86, \mathrm{df}=2,147$, $P=0.02)$, semantic fluency $(\mathrm{F}=6.30, \mathrm{df}=2,147$, $P=0.00$ ), and an equally large, though statistically somewhat more imprecise, difference on the factor reflecting the working memory component $(\mathrm{F}=2.68$, $\mathrm{df}=2,147, P=0.07)$.

The multilevel random regression analysis showed that after adjustment for age, sex, and education, three of the four cognitive factors were significantly associated with group membership (see Table II; summary linear trend for speed $\mathrm{B}=0.50, P<0.001$; for episodic memory $\mathrm{B}=0.25, P<0.01$; and for the working memory component $\mathrm{B}=0.24, P<0.01$ ). For semantic fluency, the association was neither large nor significant $(\mathrm{B}=0.09, P=0.32)$. Using the control group as the baseline, the associations were significant in both patients and relatives, but they were stronger in the patients (Table II).

Logistic regression analyses showed that the effects of the cognitive factors were independent of each other and of IQ (Table III). The factor speed was the strongest independent predictor of group membership in the comparison between patients and controls, after adjustment for age, sex, educational level, and IQ $(\mathrm{OR}=4.52$, 
95\% CI $=2.20-9.26)$, followed by the working memory component $(\mathrm{OR}=4.38,95 \% \mathrm{CI}=1.69-11.34)$, and episodic memory $(\mathrm{OR}=3.26,95 \% \mathrm{CI}=1.49-7.15)$. In the comparison between relatives and controls, the pattern of results was similar, including the order of strength of association. Exclusion of the six relatives with major depression did not change the pattern of results.

\section{DISCUSSION}

The results show that the cognitive performance of first-degree relatives of patients with a diagnosis of schizophrenia is worse than that of age-, sex-, and education-adjusted general population controls. The pattern of deficits was similar to that seen in the patients, as was the order of magnitude of the associations with, respectively, speed of information processing, the working memory component, and episodic memory. The degree of cognitive performance deficits paralleled the degree of genetic liability, in that performance of the relatives fell between that of the patients and the controls. Finally, the effects of the three cognitive factors (speed of information processing, the working memory component, and episodic memory), were independent both of each other and of IQ, indicating that these cognitive deficits represent independent risk factors. Nevertheless, the cognitive domains, as such, might well be intercorrelated, as suggested by data from Toomey and colleagues [Toomey et al., 1998].

Since the control subjects were recruited through random mailings in the local area from a listing of all eligible individuals in the general population, it is unlikely that the performance differences are due to bias in the selection of controls. Furthermore, control selection bias cannot explain why relatives' performance was intermediate to that of patients and controls.

In the univariate comparisons in Table I, the relatives did not show any change in intelligence score relative to controls, whereas the patients had lower IQ's. In the multivariate analyses presented in Table III, however, the effect of IQ in the patient group was greatly reduced after taking into account the effects of the specific cognitive factors, indicating that the specific cognitive factors were much stronger independent predictors of patient status than IQ. The relatives, however, had significantly higher IQ than the controls when the analysis was adjusted for the effects of the specific cognitive functions, indicating that their higher IQ scores tended to be obscured by the specific cognitive deficits. It is attractive to speculate that higher IQ in the relatives serves as a protective factor in the presence of genetically-mediated cognitive deficits that increase the risk for schizophrenia. Other authors have suggested that relatives may show a modest decline in IQ score [Kremen et al., 1995], but the effect of IQ in these studies was not assessed after adjustment for specific cognitive deficits. Other studies have suggested that relatives have higher $\mathrm{IQ}$, albeit only relatives of patients that are exposed to presumed environmental 
TABLE III. Independence of Association Between Cognitive Factors and Schizophrenia Risk, Adjusted For IQ in Addition to Age, Sex and Level of Education

\begin{tabular}{lcccc}
\hline \multirow{2}{*}{$\begin{array}{l}\text { Neuropsychological } \\
\text { domain }^{\text {a }}\end{array}$} & \multicolumn{2}{c}{ Relatives vs. controls } & \multicolumn{2}{c}{ Patients vs. controls } \\
\cline { 2 - 4 } \cline { 4 - 5 } Speed & OR & $(95 \% \mathrm{CI})$ & OR & $(2.20-9.26)^{* * *}$ \\
Episodic memory & 3.32 & $(1.72-6.41)^{* * *}$ & 4.52 & $(1.49-7.15)^{* *}$ \\
Semantic fluency & 2.06 & $(1.19-3.58)^{*}$ & 3.27 & $(0.73-3.08)$ \\
Working memory & 1.00 & $(0.59-1.70)$ & 1.50 & $(1.69-11.34)^{* *}$ \\
IQ score & 2.56 & $(1.29-5.01)^{* *}$ & 4.38 & $(0.96-1.09)$ \\
\hline
\end{tabular}

${ }^{\mathrm{a}}$ All factors except IQ: higher score indicates poorer performance.

${ }^{*} P<.05$.

$* * P<.01$.

$* * * P<.001$

risk factors such as pregnancy and birth complications [Gilvarry et al., 2000].

The four-factor solution that emerged from the current study is largely in accordance with previous findings from our group [Ponds, 1998], but slightly different from those by other groups, in that we found a correlation between the CST and Digit Span, while other factor analytical solutions had the Digit Span loading on a separate factor [Mirsky, 1987; Kremen et al., 1992]. Nevertheless, this does not preclude the existence of a common working memory component to the CST and Digit Span, as reported in the present paper.

Both in patients with schizophrenia and in relatives, the association with cognitive performance deficits was strongest with speed of information processing, followed by the working memory component and episodic memory. In fact, the size of the differences between cases and controls can be considered conservative, as the groups were matched for educational level, and educational attainment is likely to be reduced as a consequence of schizophrenia. The findings are consistent with other studies, suggesting that relatives have deficits that are qualitatively similar, but subtler, compared to patients with schizophrenia, especially in the domains of attention and memory [Keefe et al., 1994; Lyons et al., 1995; Faraone et al., 1995a; Faraone et al., 1999; Chen and Faraone, 2000; Faraone et al., 2000]. A likely explanation for these findings is that cognitive deficits are transmitted within families of patients with schizophrenia as markers of genetic risk or endophenotypes. The current study provided evidence that the effects of the various cognitive deficits were independent both of each other and of IQ. Thus, it is possible that there are several distinct cognitive domains of risk that either reflect separate genetic factors, or represent the pleiotropic manifestation of a single underlying genetic influence. Larger, multiple generation family studies are needed to determine to what extent these cognitive deficits are transmitted independently in families of patients with a diagnosis of schizophrenia.

\section{REFERENCES}

Brand N, Jolles J. 1985. Learning and retrieval rate of words presented auditorily and visually. J Gen Psychol 112:201-210.
Chen WJ, Faraone SV. 2000. Sustained attention deficits as markers of genetic susceptibility to schizophrenia. Am J Med Genet 97:5257.

De Bie SE. 1987. Standaardvragen 1987: Voorstellen voor uniformering van vraagstellingen naar achtergrondkenmerken en interviews [Standard questions 1987: Proposal for uniformization of questions regarding background variables and interviews]. Leiden: Leiden University Press.

Faraone SV, Kremen WS, Lyons MJ, Pepple JR, Seidman LJ, Tsuang MT 1995a. Diagnostic accuracy and linkage analysis: how useful are schizophrenia spectrum phenotypes? Am J Psychiatry 152:12861290.

Faraone SV, Seidman LJ, Kremen WS, Pepple JR, Lyons MJ, Tsuang MT 1995b. Neuropsychological functioning among the nonpsychotic relatives of schizophrenic patients: a diagnostic efficiency analysis. J Abnorm Psychol 104:286-304.

Faraone SV, Seidman LJ, Kremen WS, Toomey R, Pepple JR, Tsuang MT 1999. Neuropsychological functioning among the nonpsychotic relatives of schizophrenic patients: a 4-year follow-up study. J Abnorm Psychol 108:176-181.

Faraone SV, Seidman LJ, Kremen WS, Toomey R, Pepple JR, Tsuang MT 2000. Neuropsychologic functioning among the nonpsychotic relatives of schizophrenic patients: the effect of genetic loading. Biol Psychiatry 48:120-126.

Gilvarry C, Takei N, Russell A, Rushe T, Hemsley D, Murray RM. 2000 Premorbid IQ in patients with functional psychosis and their firstdegree relatives. Schizophr Res 41:417-429.

Gold JM, Weinberger DR. 1995. Cognitive deficits and the neurobiology of schizophrenia. Curr Opin Neurobiol 5:225-230.

Goldberg TE, Torrey EF, Gold JM. 1995. Genetic risk of neuropsychological impairment in schizophrenia: a study of monozygotic twins discordant and concordant for the disorder. Schizophr Res 17:77-84.

Harris JG, Adler LE, Young DA. 1996. Neuropsychological dysfunction in parents of schizophrenics. Schizophr Res 20:253-260.

Houx PJ, Vreeling FW, Jolles J. 1991. Age-associated cognitive decline is related to biological life-events. In: Iqbal K, McLachlan DRC, Winblad B, Wisniewski HM, editors. Alzheimer's disease: basic mechanisms, diagnosis and therapeutic strategies. Chichester: John Wiley \& Sons, Ltd. p 353-359.

Kay SR, Opler LA, Fiszbein A. 1992. Positive and negative syndrome scale (PANSS). New York: Multi-Health Systems, Inc.

Keefe RSE, Silverman JM, Roitman SEL. 1994. Performance of nonpsychotic relatives of schizophrenic patients on cognitive tests. Psychiatry Res 53:1-12.

Kendler KS, Diehl SR. 1993. The genetics of schizophrenia: a current, genetic-epidemiologic perspective. Schizophr Bull 19:261-285.

Kremen WS, Seidman LJ, Faraone SV, Pepple JR, Tsuang MT. 1992 Attention/information-processing factors in psychotic disorders. Replication and extension of recent neuropsychological findings. J Nerv Ment Dis 180:89-93.

Kremen WS, Seidman LJ, Pepple JR, Lyons MJ, Tsuang MT, Faraone SV. 1994. Neuropsychological risk indicators for schizophrenia: a review of family studies. Schizophr Bull 20:103-119.

Kremen WS, Seidman LJ, Faraone SV, Pepple JR, Lyons MJ, Tsuang MT 1995. The ' 3 Rs' and neuropsychological function in schizophrenia: 
test of the matching fallacy in biological relatives. Psychiatry Res 56:135-143.

Lezak MD. 1995. Neuropsychological assessment. Oxford: Oxford University Press.

Lukoff D, Nuechterlein KH, Ventura J. 1986. Manual for the expanded brief psychiatric rating scale. Schizophr Bull 12:594-602.

Luteijn F, van der Ploeg FAE. 1983. Handleiding Groninger Intelligentietest (GIT) [Manual Groningen Intelligence Test]. Lisse, The Netherlands: Swets \& Zeitlinger.

Lyons MJ, Toomey R, Seidman LJ, Kremen WS, Faraone SV, Tsuang MT. 1995. Verbal learning and memory in relatives of schizophrenics: preliminary findings. Biol Psychiatry 37:750-753.

McGuffin P, Farmer AE, Harvey I. 1991. A polydiagnostic application of operational criteria in psychotic illness. Development and reliability of the OPCRIT program. Arch Gen Psychiatry 48:764770 .

Mirsky AF. 1987. Behavioral and psychophysiological markers of disordered attention. Environ Health Perspect 74:191-199.

Mohamed S, Paulsen JS, O'Leary D, Arndt S, Andreasen N. 1999 Generalized cognitive deficits in schizophrenia: a study of first-episode patients. Arch Gen Psychiatry 56:749-754.

Overall JE, Gorham DE. 1962. The brief psychiatric rating scale. Psychol Rep 10:799-812.
Park S, Holzman PS, Goldman Rakic PS. 1995. Spatial working memory deficits in the relatives of schizophrenic patients. Arch Gen Psychiatry 52:821-828.

Ponds RWHM. 1998. Forgetfulness and cognitive aging. Prevalence, characteristics, and determinants. PhD thesis. Maastricht, The Netherlands: Neuropsych Publishers.

Reitan RM. 1958. Validity of the Trail Making Test as an indication of organic brain damage. Percept Mot Skills 8:271-276.

Schatz J. 1998. Cognitive processing efficiency in schizophrenia: generalized vs domain specific deficits. Schizophr Res 30:41-49.

Smith A. 1968. The Symbol Digit Modalities Test: a neuropsychological test for economic screening of learning and other cerebral disorders. Learning Disorders 36:83-91.

Spitzer R, Endicott J, Robins E. 1978. Research diagnostic criteria: rationale and reliability. Arch Gen Psychiatry 35:773-782.

STATA C. 1999. STATA statistical software 6.0. College Station, Texas.

Stroop JR. 1935. Studies of interference in serial verbal reactions. J Exp Psychol 18:643-662.

Toomey R, Faraone SV, Seidman LJ, Kremen WS, Pepple JR, Tsuang MT. 1998. Association of neuropsychological vulnerability markers in relatives of schizophrenic patients. Schizophr Res 31:89-98.

Wechsler D. 1981. Wechsler Adult Intelligence Scale.Revised. New York: Psychological Corporation. 